\title{
Modulation of the Inactivation of Voltage-Dependent Potassium Channels by cAMP
}

\author{
Sungkwon Chung ${ }^{\mathrm{a}}$ and Leonard K. Kaczmarek \\ Department of Pharmacology, Yale University School of Medicine, New Haven, Connecticut 06520
}

Modulation of voltage-dependent potassium currents can alter the shape and timing of action potentials, thereby altering neurotransmitter release. To examine the effect of a CAMP analog on potassium currents in metabolically intact cells, perforated-patch and cell-attached patch recordings were carried out using the $\mathrm{GH}_{4} \mathrm{C}_{1}$ pituitary cell line. A major component of voltage-dependent potassium current in these cells inactivates slowly, with a time constant of several seconds. Application of dibutyryl cAMP decreased this current at voltages positive to $-10 \mathrm{mV}$ and increased the rate of inactivation by approximately twofold. Single channel recordings revealed two channel types whose voltage dependence and kinetics of inactivation match those of the macroscopic current. One of these, the smaller conductance (7.5 pS) channel, was sensitive to the cAMP analog, which decreased the latency of the channel to enter a longlasting inactivated state. Ensemble averages of the activity of this channel showed that, consistent with its effect on the macroscopic current, dibutyryl cAMP increased its rate of inactivation. Somatostatin, an agent that is known to activate a serine/threonine phosphatase in these cells, completely reversed the effect of dibutyryl cAMP on the channel, while the cyclic GMP analog, dibutyryl cyclic GMP was without effect. In contrast, the rate of inactivation of the larger conductance $(\sim 19 \mathrm{pS})$ channel was not accelerated by dibutyryl cAMP. These studies indicate that different channel subtypes expressed in a single cell respond differently to elevations of CAMP, and suggest that the overall response of potassium currents to second messengers may be determined by the ratio of different channel subtypes.

[Key words: potassium channels, cAMP, inactivation, pituitary cells, $\mathrm{GH}_{4} \mathrm{C}_{1}$ cells, delayed rectifier]

The varied electrical properties of neurons and other excitable cells can be attributed to two factors. First, each cell type selects its ion channels from a large palette of genes that encode ion channels with different selectivity, voltage dependence, and kinetics. These may be mixed and matched to produce the resultant electrical phenotype. Second, protein kinases and second messenger systems modulate ion channels, allowing the same

\footnotetext{
Received Apr. 1, 1994; revised Dec. 2, 1994; accepted Dec. 12, 1994.

This work was supported by NIH Grant GM48851 to L.K.K.

Correspondence should be addressed to L. K. Kaczmarek, Department of Pharmacology, Yale University School of Medicine, 333 Cedar Street, New Haven, CT O6520.

Present address: ASAN Life Science Institute, 388-1 Poongnap-dong, Songpa-ku, Seoul 138-040, Korea.

Copyright (C) 1995 Society for Neuroscience 0270-6474/95/153927-09\$05.00/0
}

channel to behave in different ways that depend on the exposure of the cells to hormones or neurotransmitters.

Pituitary cells, like many types of neurons, undergo changes in their firing pattern and in the shape of their action potentials at the onset of periods of secretory activity. In common with pituitary cells in vivo, the electrical properties of the $\mathrm{GH}_{3}$ and $\mathrm{GH}_{4} \mathrm{C}_{1}$ pituitary cell lines are subject to modulation by a number of neurotransmitters and hormones, and serve as a model system for the study of the molecular mechanisms underlying excitability and secretion (Dubinsky and Oxford, 1985; Bauer et al., 1990; Kramer et al., 1991; Simasko, 1991a; White et al., 1991, 1993). The genes for at least four voltage-dependent potassium channels are expressed in these cells (Meyerhof et al., 1992), and the expression of one of these (Kv1.5) has been shown to be regulated potently by exposure of the cells to glucocorticoid agonists (Levitan et al., 1991; Saal et al., 1992; Takimoto et al., 1993). As yet, however, little is known about the acute actions of second messengers and related protein kinases on the characteristics of these potassium channels. In this study, we have used perforated-patch and cell-attached patch recording techniques to investigate the actions of cAMP on the voltage-dependent potassium channels in these cells. We find that, at the single channel level, there exist at least two types of slowly-inactivating potassium channels, and that the inactivation kinetics of one of these are subject to modulation by changes in cAMP levels.

\section{Materials and Methods}

Cell culture. $\mathrm{GH}_{4} \mathrm{C}_{1}$ cells were grown as follows. A stock line was maintained by growing cells in a $10 \mathrm{~cm}$ culture dish in $10 \mathrm{ml}$ of Dulbecco's modified Eagle's medium supplemented with $15 \%$ horse serum. Culture dishes were kept in a $95 \%$ air and $5 \% \mathrm{CO}_{2}$ humidified atmosphere at $37^{\circ} \mathrm{C}$. Growth medium was replaced twice a week and the cells were split (1:3 to 1:5) into subcultures once a week. At each pass some cells were plated onto $2.5 \mathrm{~cm}$ culture dishes (Corning) for electrophysiological measurements. Electrophysiological recordings were made 4-6 d after plating of the subcultures. All tissue culture media and serum were obtained from GIBCO (Grand Island, NY)

Electrophysiological measurements. For electrophysiological recordings, culture dishes on which cells were growing were first rinsed with bath buffer (see below) so as to minimize the amount of extracellular debris at the surface of the dish. Recordings were carried using on isolated cells not in contact with their neighbors. For the perforated patch modification of the wholc cell recording technique (Horn and Marty, 1988), 1-2 M $\Omega$ resistance electrodes were pulled from borosilicate glass (TW 150-4, World Precision Instruments, Sarasota, FL), and filled with a solution of nystatin $(1.5 \mu \mathrm{g} / \mathrm{ml})$. Successful perforation of the patch (access resistance $<50 \mathrm{M} \Omega$ ) was judged by the analysis of the capacitative transient produced by the application of small voltage pulses. In most of the cases the access resistances did not change during the course of an experiment. For cell-attached patches, 3-5 M $\Omega$ resistance electrodes were pulled. After filling these with pipette solution, the tips of the electrodes were dipped into Sigmacoat solution (Sigma, St. Louis). 
A
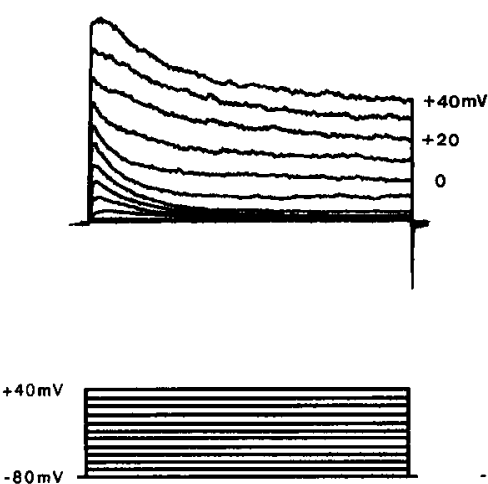

B

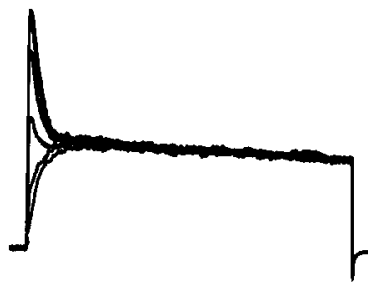

C

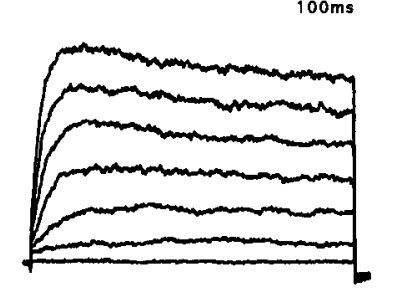

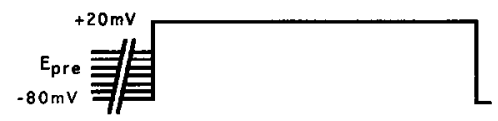

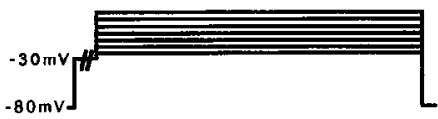

Figure I. Activation of outward currents in $\mathrm{GH}_{4} \mathrm{C}_{1}$ cells by depolarizing voltage pulses. Nystatin-perforated patches were obtained as described in Materials and Methods. A, The patch was held at $-80 \mathrm{mV}$, and $500 \mathrm{msec}$ voltage steps were applied to potentials between $-70 \mathrm{mV}$ to $40 \mathrm{mV}$ in $10 \mathrm{mV}$ increments. The interpulse interval was $30 \mathrm{sec}$. The current traces for pulses to $+40,+20$, and $0 \mathrm{mV}$ pulses are indicated in the figure. $B$, Depolarizing prepulses $(100 \mathrm{msec})$ ranging from $-80 \mathrm{mV}$ to $-20 \mathrm{mV}$ in $10 \mathrm{mV}$ increments were applied to inactivate the transient currents. The test pulse was a $500 \mathrm{msec}$ pulse to $+20 \mathrm{mV}$. Significant inactivation of the transient current by these prepulses starts with prepulses to about $-50 \mathrm{mV}$. The interpulse interval was $30 \mathrm{sec}$. $C$, A $100 \mathrm{msec}$ prepulse to $-30 \mathrm{mV}$ was applied to inactivate the transient currents before evoking the delayed rectifier currents with $500 \mathrm{msec}$ pulses to potentials between $-20 \mathrm{mV}$ to $+40 \mathrm{mV}$ in $10 \mathrm{mV}$ increments.

The bath solution used for perforated patch and cell-attached patch recordings contained $140 \mathrm{~mm} \mathrm{NaCl}, 5 \mathrm{mM} \mathrm{KCl}, 3 \mathrm{mM} \mathrm{MgCl}_{2}, 10 \mathrm{~mm}$ glucose, and $10 \mathrm{~mm}$ HEPES (pH 7.4). The pipette solution for the perforated patch experiments contained $150 \mathrm{mM} \mathrm{KCl,} 3 \mathrm{mM} \mathrm{MgCl}_{2}$, and $10 \mathrm{~mm}$ IILPES (pII 7.4). The pipette solution for the cell-attached patch experiments was the same as the bath solution except that it included $1 \mu \mathrm{M}$ apamin and $10 \mathrm{nM}$ tetrodotoxin (Sigma).

In experiments testing the effects of cyclic nucleotides, concentrated stock solutions of dibutyryl cAMP and dibutyryl cGMP (200 mM) were first made in distilled water. Somatostatin and all of the membrane permeant cAMP analogs were obtained from Sigma. Drugs were applied by pipette application of more concentrated stock solutions, and the bath was not perfused during the course of the experiments.

The current signals from voltage-clamp experiments were filtered at $1 \mathrm{kHz}$ with an eight-pole Bessel filter, digitized at $2 \mathrm{kHz}$ and stored on an MS-DOS compatible computer. The computer was equipped with a Labmaster A/D board coupled to an Indec IBM instrumentation interface, and used Indec BASIC-FASTLAB software (Sunnyvale, CA). Studies of drug effects and kinetic analysis of single channel activity were carried out using individual patches that contained between one and four channels. The single channel recordings from cell-attached patches were filtered at $200 \mathrm{~Hz}$ and digitized at $1 \mathrm{kHz}$. The slope conductances for two channel types described were calculated using a linear fit to a plot of the magnitude of single channel events at potentials between +10 $\mathrm{mV}$ and $+60 \mathrm{mV}$ positive to the resting potential. Inactivation time constants were determined by fitting the falling phase of the current trace, after deletion of the first $200 \mathrm{msec}$ of the trace, to one exponential decay. In brief, cursors were placed at $200 \mathrm{msec}$ and at the end of the pulse and single exponentials fitted to the data as shown in Figure $5 B$, using the BASIC FASTLAB FIT program. All individual current traces were leak subtracted, after acquisition, before generating ensemble averages by summation of individual single channel traces.

\section{Results}

Separation of the potassium currents in $\mathrm{GH}_{4} \mathrm{C}_{1}$ cells

Because conventional whole-cell patch-clamp recordings can compromise the normal function of second messenger pathways, we used the perforated patch technique (Horn and Marty, 1988) to record potassium currents in metabolically intact $\mathrm{GH}_{4} \mathrm{C}_{1}$ cells. Separation of voltage-activated potassium currents from calcium-activated potassium currents was achieved by replacing $\mathrm{Ca}^{2+}$ in the external solution by $\mathrm{Mg}^{2+}$ (Simasko, 1991b). Figure $1 A$ shows that depolarizing voltage steps from a holding potentials of $-80 \mathrm{mV}$ activate both transient and sustained potassium currents. The transient potassium current is first detected with steps to $-50 \mathrm{mV}$, while the more sustained current starts to activate at about $-20 \mathrm{mV}$. To differentiate the sustained current from the transient current, we use to term "delayed rectifier" to denote the sustained component. As reported previously for these cells (Simasko, 1991b), the ratio of the transient current to the delayed rectifier current was found to vary from cell to cell. To separate these two currents, depolarizing prepulses $(100 \mathrm{msec})$ were given to potentials between $-80 \mathrm{mV}$ and $-20 \mathrm{mV}$ before applying a test pulse to $+20 \mathrm{mV}$. Figure $1 B$ shows that a prepulse to -30 $\mathrm{mV}$ induces almost full inactivation of the early transient current, without causing any decrement in the later sustained potassium current. We found, however, that a gradual decrement of delayed rectifier currents occurred using repetitive depolarizing voltage pulses with interpulse intervals shorter than $30 \mathrm{sec}$ (data not shown). Thus, the interval between individual pulses was always kept to $30 \mathrm{sec}$ to provide time for these currents to recover fully from inactivation. Figure $1 C$ shows the delayed rectifier currents evoked at series of potentials up to $+40 \mathrm{mV}$, using a $100 \mathrm{msec},-30 \mathrm{mV}$ prepulse to inactivate the transient current.

The delayed rectifier in $\mathrm{GH}_{4} \mathrm{C}_{1}$ cells undergoes slow inactivation during sustained depolarization. Figure $2 A$ shows the current evoked by a voltage step from a holding potential of -80 $\mathrm{mV}$ to $+40 \mathrm{mV}$ for a period of $500 \mathrm{msec}$. The decay of this current during the pulse has been fit with a single exponential with a time constant of $2000 \mathrm{msec}$, which is shown as the solid line superimposed on the current trace. This rate of inactivation is relatively independent of voltage. Figure $2 B$ shows that when the currents evoked by steps to $0,+20$, and $+40 \mathrm{mV}$ are scaled to size, the decaying phases of the three currents are superimposed, indicating that the inactivation time constants are identical over this range of voltages.

\section{Modulation of potassium current in perforated patches} Bath applications of the membrane permeant cAMP analog, dibutyryl cAMP ( $2 \mathrm{mM}$ ), decreased the amplitude of delayed rec- 

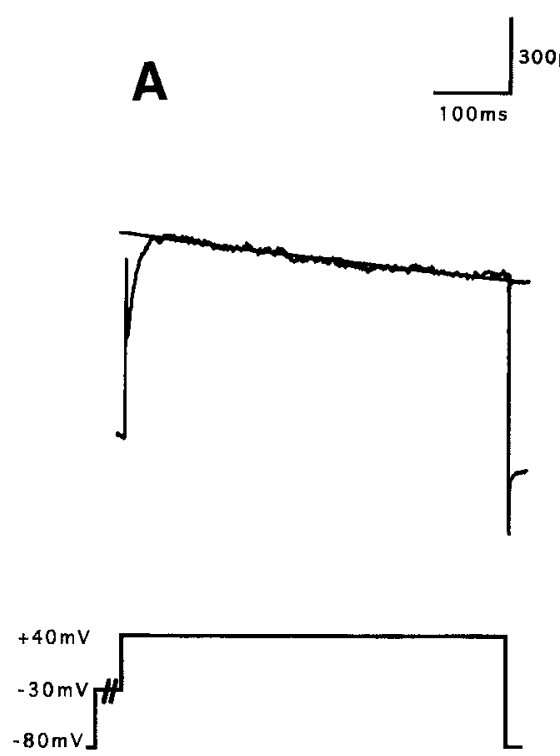

B
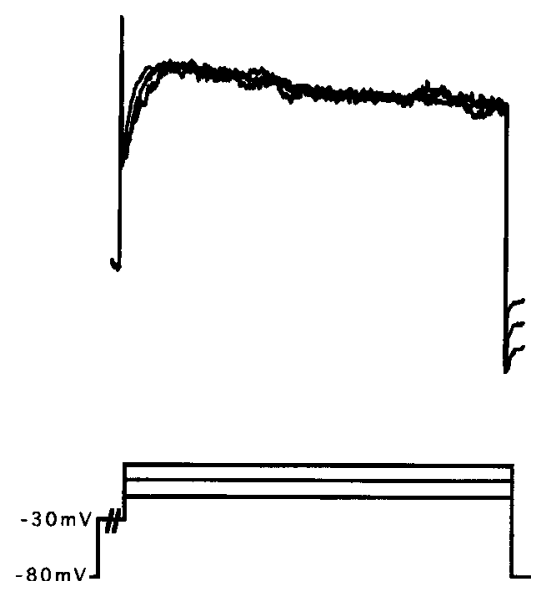

Figure 2. Inactivation of the delayed rectifier currents in nystatin-perforated patches. $A$, Delayed rectifier potassium current was activated by a pulse to +40 $\mathrm{mV}$ using the prepulse protocol of Figure $1 C$. The decay of the current was fit with a single exponential shown as a solid line. $B$, The delayed rectifier current traces evoked by voltage steps to $0,+20,+40 \mathrm{mV}$ are shown scaled to size. tifier currents at all voltages positive to $-10 \mathrm{mV}$ in $\mathrm{GH}_{4} \mathrm{C}_{1}$ cells recorded with the perforated patch technique. $(N=6)$. Figure $3 \mathrm{~A}$ shows currents activated by steps to $+40 \mathrm{mV}$ from a holding potential of $-80 \mathrm{mV}$, before and $10 \mathrm{~min}$ after the addition of dibutyryl cAMP. The peak currents and the currents recorded at the end of a $500 \mathrm{msec}$ pulse before and after application of the cAMP analog are shown as a function of voltage in Figure $3 B$. The currents recorded at the end of the pulse are decreased to a greater extent than the peak currents, indicating that application of dibutyryl cAMP produces an increase in the rate of inactivation of the current. At $+40 \mathrm{mV}$, the currents at the end of the pulse were significantly reduced by $26.3 \pm 4.3 \%( \pm \mathrm{SE} ; n=$ $3, p<0.005, t$ test), while the peak currents were decreased by only $11.4 \pm 5.5 \%(p<0.05)$. When single exponential curves were fitted to the inactivating phase of the currents, the time constant for inactivation was found to be reduced from $2000 \pm$ $95 \mathrm{msec}$ to $920 \pm 30 \mathrm{msec}$. The decaying phases of currents evoked by steps to $0,+20$, and $+40 \mathrm{mV}$ in the presence of dibutyryl cAMP could be superimposed when scaled to size (Fig. 3D), indicating that, as for the control currents, the rate of inactivation remains relatively independent of voltage. The effects of dibutyryl cAMP on amplitude and inactivation rate could be detected 5 min after addition of the analog, and reached a maximum within $15-30 \mathrm{~min}$ (Fig. 3C).

Perforated patch recordings were also carried out in current clamp mode to test the effect of dibutyryl cAMP on membrane potential. The resting potential of the cells was found to be $-40.9 \pm 2.6 \mathrm{mV}( \pm \mathrm{SD} ; n=11)$ and did not change with exposure to the cAMP analog for over $30 \mathrm{~min}$.

\section{The delayed rectifier potassium channel in cell-attached patches}

Cell-attached patch-clamp recordings were carried out to detect potassium channel activity at the single channel level. The pipette solution for the cell-attached patch contained $140 \mathrm{mM}$ $\mathrm{NaCl}, 5 \mathrm{~mm} \mathrm{KCl}, 3 \mathrm{~mm} \mathrm{MgCl}_{2}$, and $10 \mathrm{~mm} \mathrm{HEPES} \mathrm{(pH} \mathrm{7.4).}$ In addition, apamin ( $1 \mu \mathrm{M})$, and tetrodotoxin $(10 \mathrm{nM})$ were included in the pipette to block the small conductance $\mathrm{Ca}^{2+}$-activated potassium channels (Ritchie, 1987) and sodium chanmels (Dubinsky and Oxford, 1984). Under these conditions we re- corded the activity of two channel types whose properties matched those of the sustained potassium currents, and their properties will be described below. In several preliminary experiments, $1 \mathrm{mM} \mathrm{Ca}{ }^{2+}$ was included in the pipette solution in the absence of apamin. Under these conditions large conductance (about $40 \mathrm{pS}$ ), noninactivating channels were recorded frequently (data not slown). These channels were never observed in the absence of $\mathrm{Ca}^{2+}$ in the pipette solution. It is likely that they are the calcium-activated potassium channels described by Lang and Ritchie (1987).

The pipette potential for cell-attached recordings was held at $+60 \mathrm{mV}$ with respect to bath solution, such that the membrane was at a potential $-60 \mathrm{mV}$ hyperpolarized from rest. Since the resting potential (RP) of the cells was close to $-40 \mathrm{mV}$, the membrane potential experienced by channel proteins at the holding potential was near $-100 \mathrm{mV}$. Voltage-dependent channels were activated by depolarizing voltage pulses lasting several seconds. Rapidly inactivating channels (whose activity lasted less than $200 \mathrm{msec}$ ) and two classes of slowly inactivating channels (lasting several seconds) were activated in the cell attached patches. The rapidly inactivating channels are likely to correspond to the transient currents recorded in perforated patches. As these channels inactivate much faster than the slowly inactivating channels, which are to be described below, we did not attempt to block these channels in cell-attached patches. Since the activity of the delayed rectifier channels in the cell-attached patches lasted for several seconds before entering inactivation, the depolarizing pulses were held for 3-7 sec, and all kinetic analysis was carried out after excluding the first $200 \mathrm{msec}$ of recordings.

Voltage pulses were applied once every minute. As was the case for the recordings of macroscopic current, this long interpulse interval was required to prevent accumulation of inactivation by repetitive depolarizing pulses. Two different potassium channels whose characteristics matched those of the delayed rectifier currents were observed in these cell-attached patches (Fig. 4). They were easily distinguished by their open channel amplitude as depicted in Figure $4 A$, where both of the channel types are present in the same patch, and were activated by 3 sec pulses to $\mathrm{RP}+50 \mathrm{mV}$. If we assume that the resting potentials of the 
A
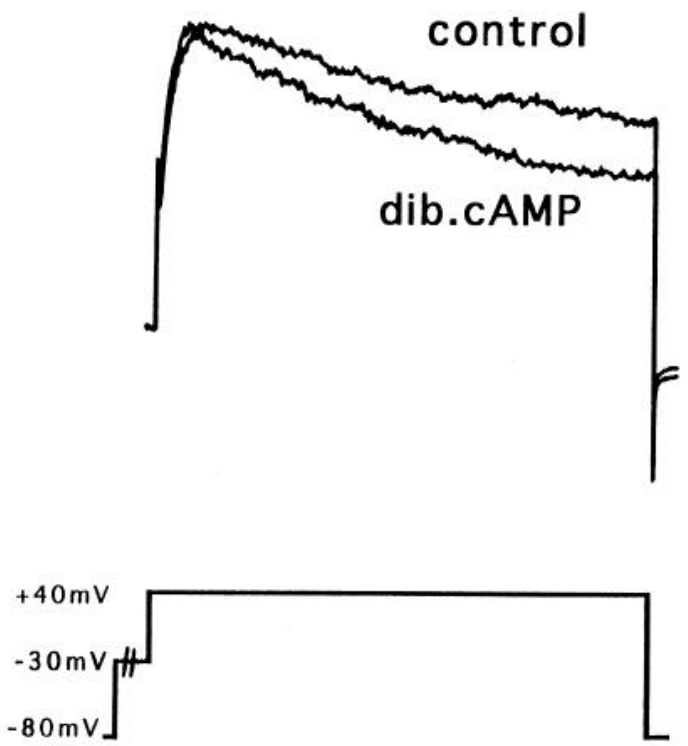

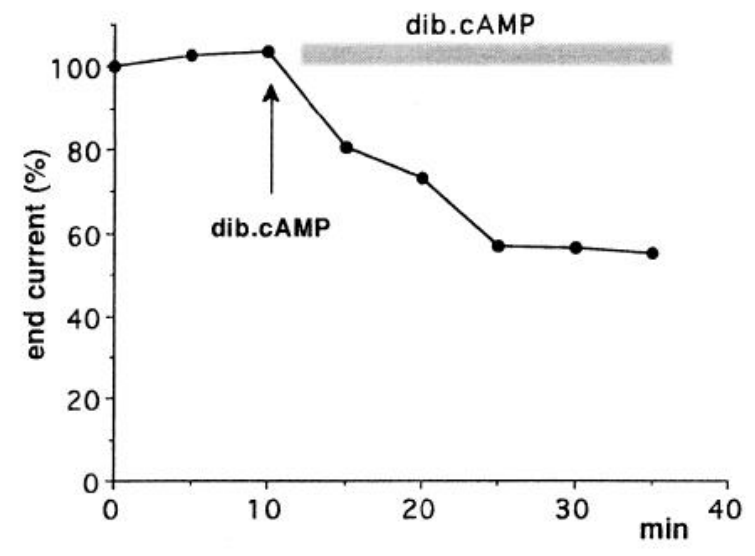

$300 \mathrm{pA}$

B

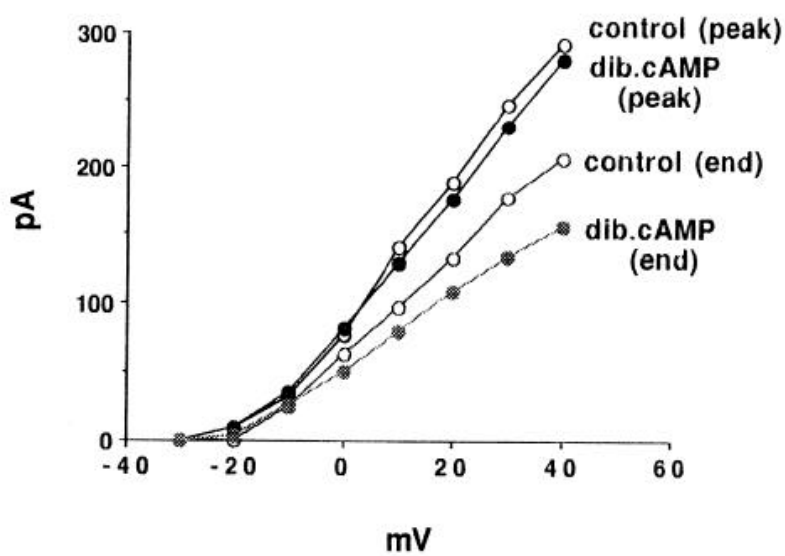

D
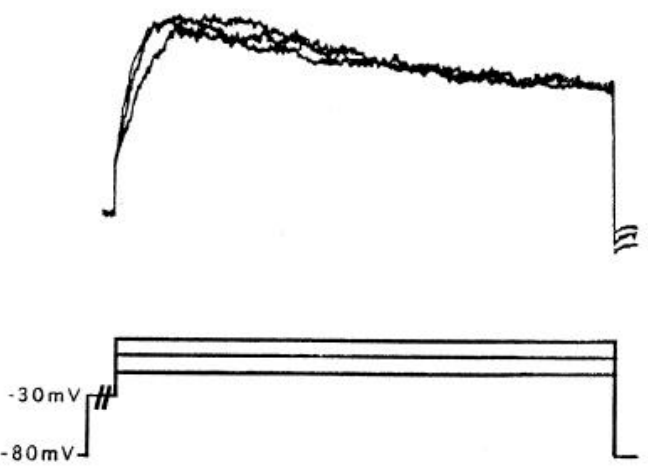

Figure 3. The effect of dibutyryl cAMP on the delayed rectifier current in a nystatin-perforated patch. A, The upper trace shows the delayed rectifier potassium current activated by a $500 \mathrm{msec}$ pulse to $+40 \mathrm{mV}$ using the prepulse protocol of Figure 1 . The lower trace shows the current $10 \mathrm{~min}$ after the addition of $2 \mathrm{~mm}$ dibutyryl cAMP to the bath. $B$. Current-voltage relations for the peak currents, and the currents at the end of the $500 \mathrm{msec}$ pulses, before and after the addition of dibutyryl cAMP. $C$, The time course of the effect of dibutyryl cAMP on the currents recorded at the end of $500 \mathrm{msec}$ pulses. Currents at $+40 \mathrm{mV}$ were evoked at $5 \mathrm{~min}$ intervals and normalized to the current measured at the start of the experiment. $D$, The delayed rectifier current traces evoked by voltage steps to $0,+20,+40 \mathrm{mV}$ after exposure of the cell to dibutyryl cAMP are scaled to size.

cells was $-40 \mathrm{mV}$ (as was found in perforated patch recordings), these pulses correspond to a membrane potential of +10 $\mathrm{mV}$. The open channel currents at this potential were 1.6 pA for the larger channel, and $0.6 \mathrm{pA}$ for the smaller channel. After opening at the onset of the 3-7 sec depolarizing pulses, both of the channel types inactivated, as manifest by the onset of longlived closed states $(>500 \mathrm{msec}$ ) (Fig. $4 B, C$ ). For example, the first trace in Figure $4 A$ shows that both of the channels are active at the beginning of the pulse, and later, after the larger conductance channel had inactivated, only smaller conductance channels remain active. For both channel types, however, occasional reopenings from the inactivated state could occur (e.g., second trace in Fig. $4 A$, third trace in Fig. $4 B$ ).

Most cell-attached patches that we recorded had more than one smaller conductance channel. In contrast, the larger conductance channel was encountered much less frequently than the 

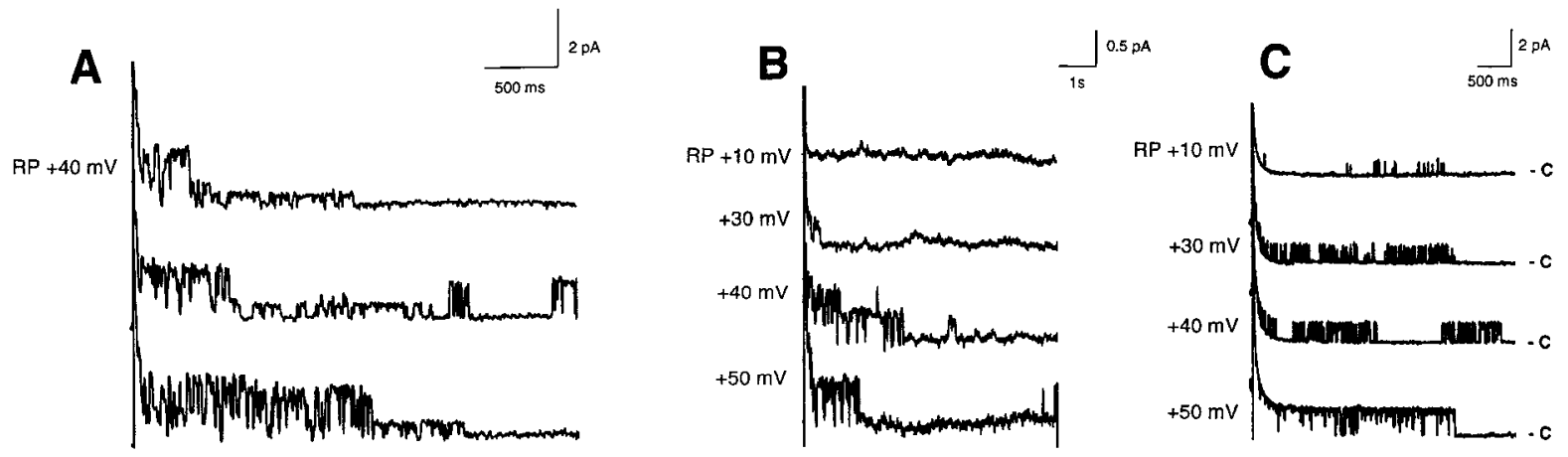

Figure 4. Single-channel currents in a cell-attached patch. A, A patch containing both the larger and the smaller conductance channels. The patch was held at RP $-60 \mathrm{mV}$ and channel activity was evoked by depolarizing the patch to RP $+40 \mathrm{mV}$. The 3 sec pulses were applied at intervals of 1 min. The closed-channel current levels $(C)$ are indicated by short bars. $B$, Records of the smaller conductance channel in a cell-attached patch. The patch was held at RP $-60 \mathrm{mV}$ and channel activity was evoked by depolarizing the membrane for 7 sec. Potentials indicated are depolarizations relative to the resting potential. $C$, Records of the larger conductance channel recorded with the same protocol as in $B$.
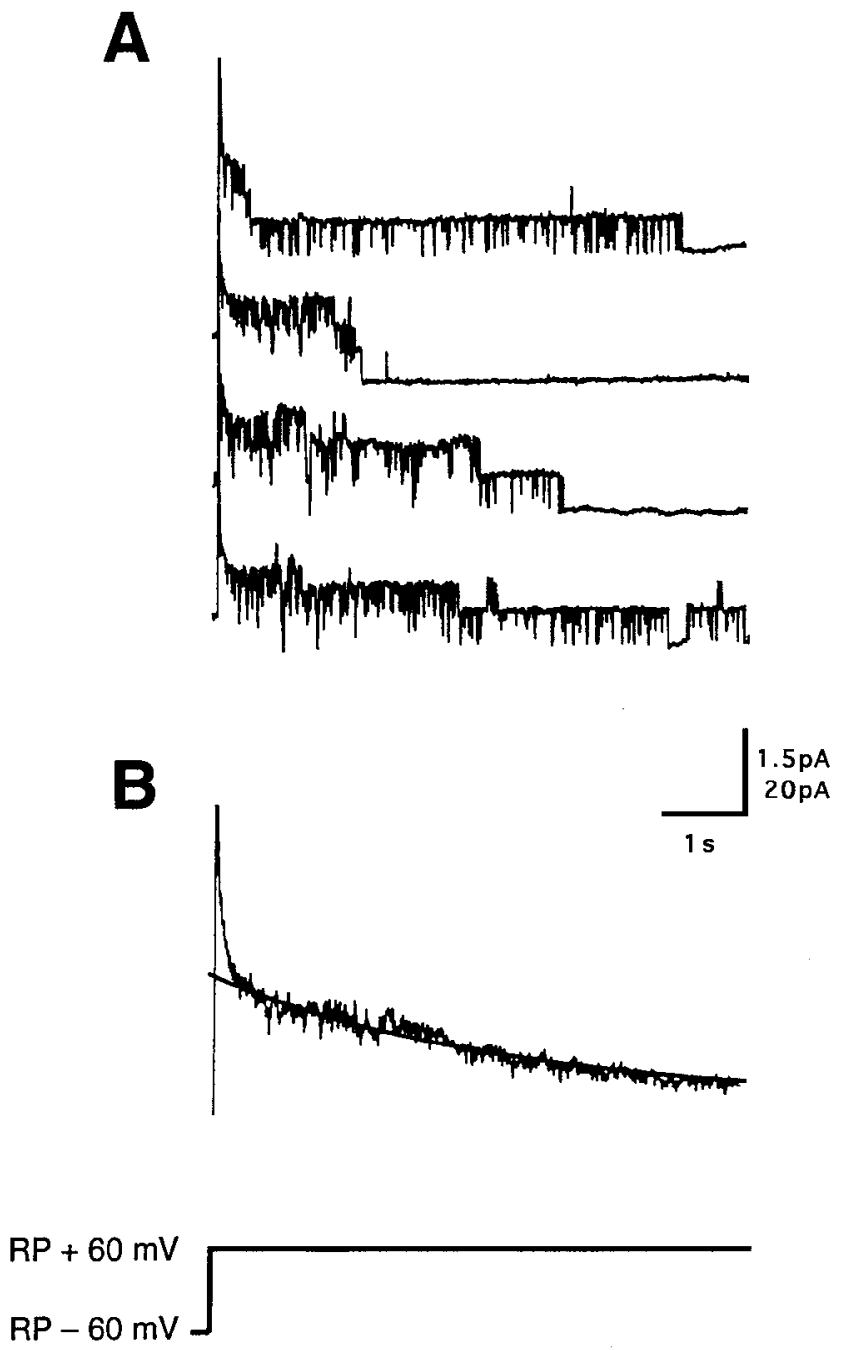

Figure 5. Activity of the smaller conductance channel in a cell-attached patch that contained only smaller conductance channels. $A$, The patch was held at RP - $60 \mathrm{mV}$ and channel activity was evoked by depolarizing the patch to $\mathrm{KP}+60 \mathrm{mV}$ for $7 \mathrm{sec}$. Pulses were applied once a minute. $B$, The ensemble average current for this channel was obtained by adding 15 successive traces. A single exponential was used to fit the decay of the ensemble average current, and is shown as a solid line in the figure. smaller one. Only six of thirty patches that had the smaller conductance channel also had the larger channel. Therefore, the number of patches having only the larger conductance channel without the smaller one was very small (only 2 out of 32 patches). The majority of the experiments described in the remainder of this paper therefore focus on the smaller conductance channels. Figure $4 A$ shows channel opening probability at different membrane voltages. Significant activation of channel activity is detected at potentials positive to $-10 \mathrm{mV}$, which is similar to the delayed rectifier currents recorded in perforated patches (Fig. $2 B$ ). The mean slope conductance for these channels, calculated from three different patches, was $7.5 \pm 0.5 \mathrm{pS}$ ( $\pm \mathrm{SE}$ ).

As was also the case for the macroscopic delayed rectifier currents, the activity of the smaller conductance channels inactivated at all voltages. Figure $5 A$ shows recordings of a cellattached patch with at least four smaller conductance channels activated by $7 \mathrm{sec}$ depolarizing voltage pulses. Figure $5 B$ shows the ensemble average of the activity of these channels obtained by adding the responses to 15 successive pulses. The ensemble average current decayed during the maintained depolarization, and this decay rate could be fit with a single exponential, as is shown by the superimposed solid line in Figure $5 B$. The average inactivation time constant is $3500 \mathrm{msec}$ for this patch, which is similar to, although slightly longer than, the inactivation rate of the delayed rectifier potassium current recorded with the perforated patch technique.

\section{Modulation of potassium channels in cell-attached patches}

Application of dibutyryl cAMP produced an increase in the rate of inactivation of the smaller conductance channels recorded in cell-attached patches. The left-hand column of Figure 6 shows representative traces of control channel activities evoked by depolarizing voltage pulses to RP $+50 \mathrm{mV}$. The channel opens at the onset of the pulse, and undergoes a period of bursting during which the opening probability is high for a variable period of time before the channel enters a long-lasting inactivated state. For the purposes of analysis, entry into the inactivated state was assumed to have occurred when the channel remained closed for at least $500 \mathrm{msec}$. In control conditions, channels sometimes failed to inactivate during the $7 \mathrm{sec}$ pulse (top trace, Fig. $6 \mathrm{~A}$ ) or inactivated at least $1 \mathrm{sec}$ after the onset of the pulse (remaining traces in Fig. 6A). Figure $6 B$ shows six representative traces of 


\section{A \\ B C}
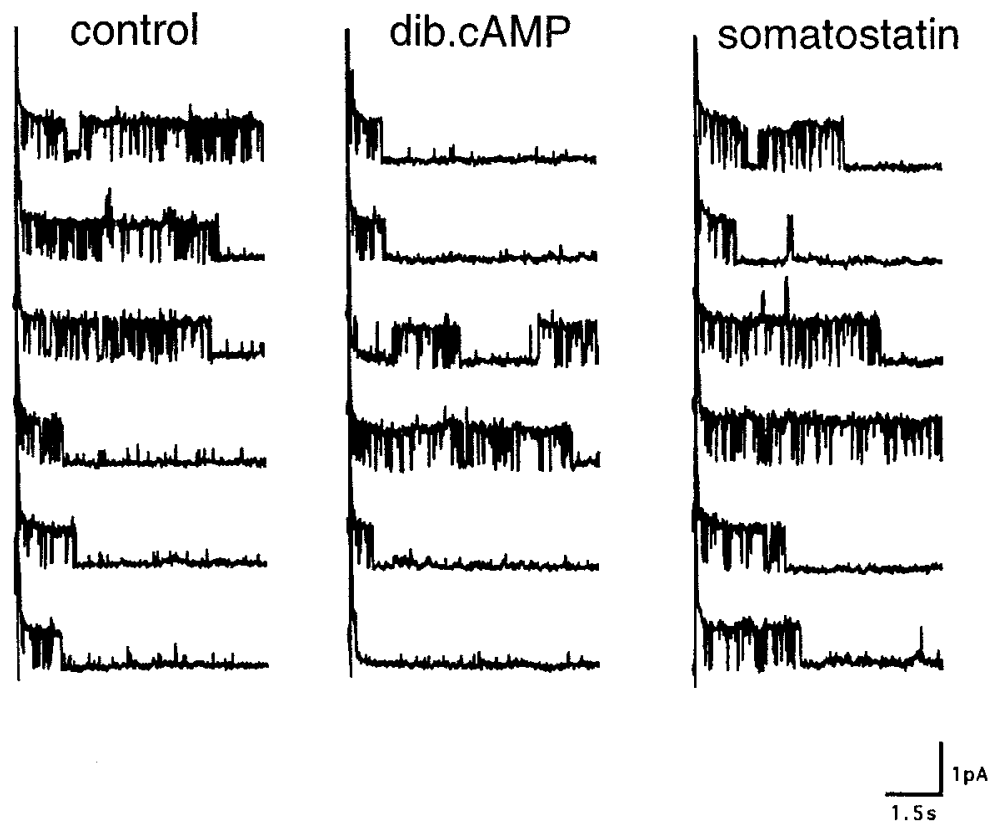

Figure 6. Modulation of the smaller conductance delayed rectifier channels in a cell-attached patch by dibutyryl cAMP and sontalostatin. The patch, was held at RP-60 mV and channel activity was evoked by depolarizing the patch to $\mathrm{KP}+50 \mathrm{mV}$. The $7 \mathrm{sec}$ pulses were applied once a minute $A$. Single channel activity before the addition of dibutyryl cAMP. $B$, Addition of dibutyryl cAMP causes the channel to inactivate more rapidly. The first trace show activity of the channel $10 \mathrm{~min}$ after the addition of $2 \mathrm{~mm}$ dibutyryl c $\triangle M P$ to the bath solution. The 2nd through 6th traces are the successive responses after the first trace separated by 1 min interpulse intervals. $C$, Somatostatin reverses the effect of dibutyryl cAMP. Successive traces show the activity of the channel beginning 7 minutes after the addition of $1 \mu \mathrm{M}$ somatostatin to the bath solution in the continued presence of dibutyryl cAMP. (Occasional openings of another channel are detected in these traces (e.g., 2nd trace of $A$ and 3 rd trace of $C$ ). Because, however, these openings are very brief, they are likely to represent a different type of channel activity). $D$ and $E$, Ensemble average currents for chamnel activity in the presence of dibutyryl cAMP and somatostatin. Ensemble average currents were calculated for the same patch as in $A-C ; 15$ successive channel responses were summed for each condition. The closed channel current levels are shown as solid lines in each panel. $D$, The upper trace shows the ensemble average current for the control, and the lower trace shows the ensemble average after the addition of $2 \mathrm{~mm}$ dibutyryl cAMP. $E$, Superimposed ensemble average currents for the control and after the addition of somatostatin in the continued presence of dibutyryl cAMP. The control ensemble average is the same as in $D$.

D

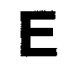

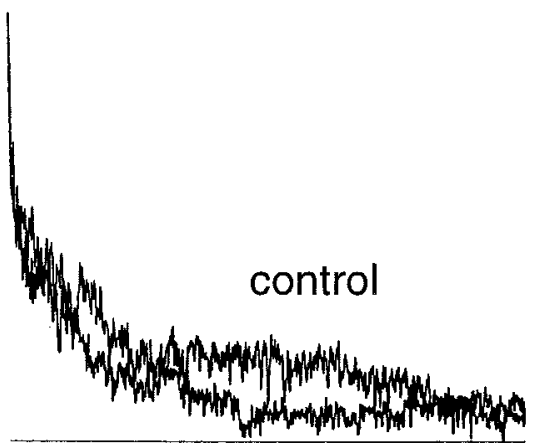

dib.cAMP

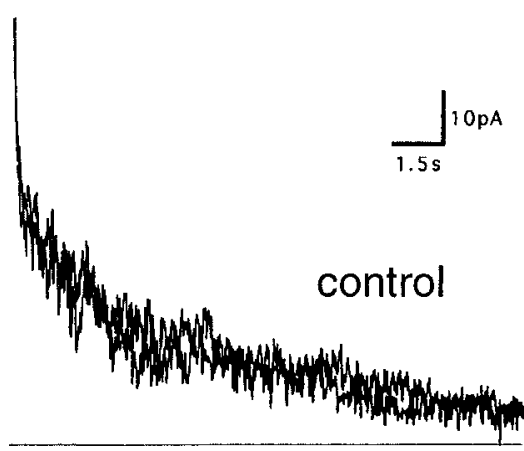

dib.cAMP + somatostatin the activity of the same channel several minutes after the addition of dibutyryl cAMP to the bath solution. The channel now inactivates faster than in the control, and, in the majority of traces shown (traces 1,2,5, and 6, Fig. $6 B$ ) enters the inactivated state in less than $1 \mathrm{sec}$.

To quantify the effect of dibutyryl cAMP, we measured the latency from channel opening at the onset of the pulse to the first long closure (longer than $500 \mathrm{msec}$ ). On those occasions when the channel failed to inactivate during a pulse, $7 \mathrm{sec}$ was taken as the inactivation time for that trace. This mean latency to inactivation was $2.61 \pm 0.56 \mathrm{sec}(\mathrm{SE} ; n=15)$ for control traces and was reduced to $1.45 \pm 0.39 \mathrm{sec}$ after dibutyryl cAMP $(p<0.03)$. Similar results were obtained in seven experiments.

The ensemble average currents for the above channel are shown in Figure $6 D$. The rate of inactivation of the average current for three sets of 15 control traces can be fitted with an exponential with a time constant of $2.34 \pm 0.20 \mathrm{sec}$ (SE; $n=$ 3 patches that had only a single channel). As expected from inspection of the single channel records, the ensemble average current after the addition of dibutyryl cAMP inactivates more rapidly (Fig. $6 D$ ), and the time constant for inactivation changes to $1.28 \pm 0.09 \mathrm{sec}(\mathrm{SE} ; n=3$ ). Therefore, the effect of dibutyryl cAMP on the smaller conductance channel in cell-attached patches is the same as that on the macroscopic delayed rectifier current, in that it increases the inactivation rate, and, as a result, decreases the amplitude of the current.

The neuropeptide somatostatin is known to activate a serine/ threonine protein phosphatase in $\mathrm{GH}_{4} \mathrm{C}_{1}$ cells (White et al., 


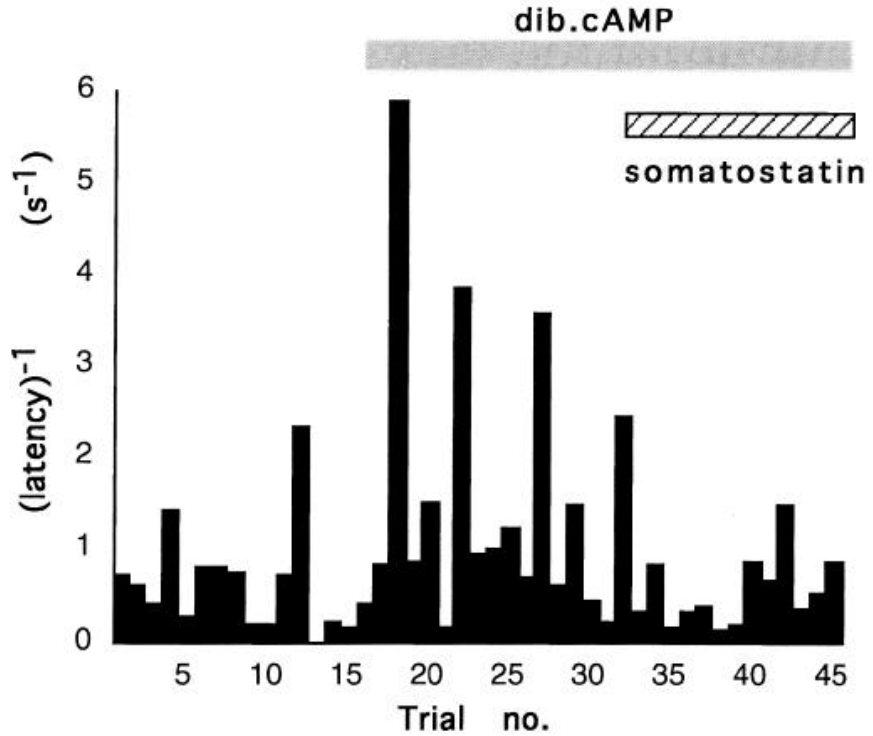

Figure 7. Time course of the actions of dibutyryl cAMP and somatostatin on the rate of inactivation of the smaller conductance channel. The reciprocal of the latency to inactivation was obtained, as described in Results, for consecutive individual traces. Trials were separated by intervals of $1 \mathrm{~min}$. The cell-attached patch contained one smaller conductance channel and no larger conductance channels.

1991). Activation of such a phosphatase could reverse actions of cAMP that are mediated by the cAMP-dependent protein kinase. To test whether the effect of dibutyryl cAMP on the smaller conductance channels could be reversed by activating this protein phosphatase, somatostatin was added to the external medium of cells that had already been exposed for dibutyryl cAMP for $25 \mathrm{~min}$. Figure $6 C$ shows the single channel activities from the same patch as in Figure $6, A$ and $B$. Seven minutes after the addition of $1 \mu \mathrm{M}$ somatostatin, in the continued presence of dibutyryl cAMP, channel activity recovered to the control pattern. The latency to inactivation, measured as described above, returned to $2.91 \pm 0.56 \mathrm{sec}$ after the addition of somatostatin, a value that is not significantly different from that for the control traces $(2.61 \pm 0.56 \mathrm{sec})$. Figure $6 E$ shows superimposed ensemble currents for control traces and those after the addition of dibutyryl cAMP and then somatostatin. The two traces overlap, indicating that somatostatin reverses the effect of dibutyryl cAMP on the rate of inactivation. Application of somatostatin alone, without prior addition of dibutyryl cAMP, did not produce any changes in the activity of the channels (six out of six experiments). Moreover, prior to the addition of somatostatin, the effect of dibutyryl cAMP remained stable for as long as we could hold the patches.

The time course of the actions of dibutyryl cAMP and of somatostatin on single channel activity is shown in Figure 7, which plots the reciprocal of the latency to inactivation in consecutive individual traces before and after exposure to these agents. This reciprocal provides a measure of the rate of inactivation at the microscopic level.

To test the specificity of the action of dibutyryl cAMP, we compared its action to that of dibutyryl cGMP, a membrane permeant cGMP analog. When $2 \mathrm{~mm}$ dibutyryl cGMP was added to cells with cell-attached patches containing the smaller conductance channels, we found no changes in channel activity in seven out of seven patches.
Dibutyryl cAMP was also tested on the larger conductance channels, which had a mean slope conductance of close to 19 $\mathrm{pS}$. There were no evident changes in the activity of this channel in five out of five cell-attached patches, although only one of these patches contained a single large conductance channel in the absence of the smaller conductance channel. Figure $8 A-D$ shows representative traces with ensemble averages before and after exposure to dibutyryl cAMP and Figure $8 E$ shows the time course of the latency to inactivation. Although we cannot rule out that dibutyryl cAMP causes some change in the kinetic behavior of the larger conductance channel, it does not appear to produce an increase in the rate of inactivation as is the case for the smaller conductance channels.

\section{Discussion}

Both voltage-dependent and calcium-dependent potassium currents have previously been described in $\mathrm{GH}_{3}$ and $\mathrm{GH}_{4} \mathrm{C}_{1}$ cells (Dubinsky and Oxford, 1984, 1985; Oxford and Wagoner, 1989; Simasko, 1991b; White et al., 1991, 1993). In $\mathrm{GH}_{3}$ cells, it has been shown that the net potassium current can be separated into rapidly inactivating A-current components (inactivation time constants of $50 \mathrm{msec}$ and $500 \mathrm{msec}$ ), delayed rectifier-like components (inactivation time constant of $2-3 \mathrm{sec}$ ), and sustained calcium-dependent potassium currents. (Simasko, 1991b). In our studies we used perforated patch recording to ensure metabolically intact cells. We found that at the level of macroscopic currents, the voltage-dependent currents in $\mathrm{GH}_{4} \mathrm{C}_{1}$ cells are generally similar to those in $\mathrm{GH}_{3}$ cells. At the single channel level, at least two type of unitary activity, with conductances of 7.5 and $19 \mathrm{pS}$, contribute to the delayed rectifier currents. In addition we have found that the amplitude and kinetics of the delayed rectifier current are modulated by changes in cAMP levels. This modulation can be accounted for by the properties of the smaller conductance channel.

Two potassium channels whose genes have been isolated are known to be expressed in $\mathrm{GH}_{3}$ and $\mathrm{GH}_{4} \mathrm{C}_{1}$ cells. These are the Kv1.4 and the Kv1.5 channels (Levitan et al., 1991; Meyerhof et al., 1992). In addition, use of the polymerase chain reaction has suggested that $\mathrm{Kv} 2.1$ and $\mathrm{Kv} 4.1$ may also be expressed at some level in $\mathrm{GH}_{3} / \mathrm{B}_{6}$ cells. The properties of the $\mathrm{Kvl} 1.4$ channel when expressed in frog oocytes closely match those of the transient A-current in $\mathrm{GH}_{3}$ cells (Meyerhof et al., 1992). In contrast, the Kv1.5 channel expressed in oocytes or mammalian cell lines behaves as a delayed rectifier whose properties resemble those of the smaller conductance cAMP-regulated channel that we have now described (Swanson et al., 1990; Snyders et al., 1993; Saal et al., 1993). The voltage-dependence of Kv1.5 is close to that of the $\mathrm{GH}_{4} \mathrm{C}_{1}$ delayed rectifier, starting to activate at potentials between -30 and $-20 \mathrm{mV}$. The unitary conductance of $\mathrm{Kv} 1.5$ expressed in a fibroblast cell line is $6.0-7.5 \mathrm{pS}$, close to that of the smaller conductance $\mathrm{GH}_{4} \mathrm{C}_{1}$ channel. In addition, the $\mathrm{Kv} 1.5$ protein has multiple consensus sites for phosphorylation by the cAMP-dependent protein kinase. When expressed in fibroblasts, the rate of inactivation of $\mathrm{Kvl} .5$ is accelerated by activation of the cAMP-dependent protein kinase in a manner similar to that of the $7.5 \mathrm{pS} \mathrm{GH}_{4} \mathrm{C}_{1}$ channel (Saal et al., 1993; Saal, Chung, and Kaczmarek, unpublished data). Thus it is possible that the Kv1.5 protein contributes, either as a homomultimer or as part of a heteromultimer, to the $\mathrm{GH}_{4} \mathrm{C}_{1}$ cAMP-regulated channel. Definitive proof of this will, however, require techniques that eliminate the Kv1.5 protein from the cells.

It is likely that the effect of dibutyryl cAMP on the $7.5 \mathrm{pS}$ 
A

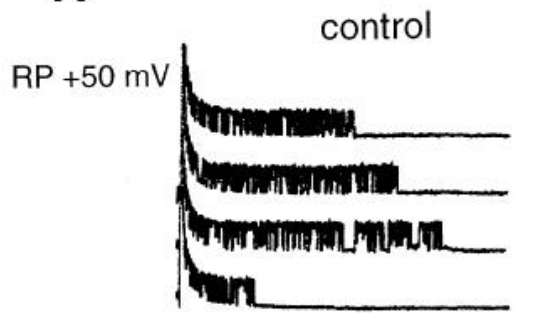

C

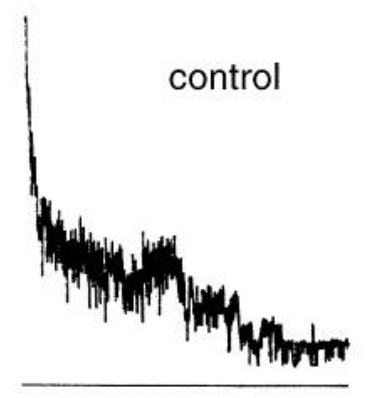

B
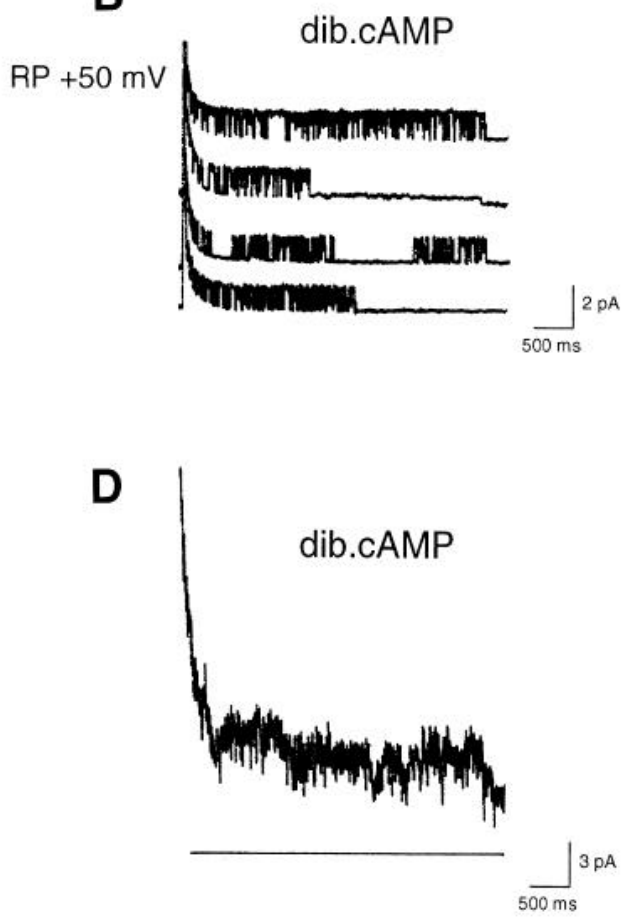

Figure 8. Lack of effect of dibutyryl cAMP on the latency to inactivation for the larger conductance channel. The patch was held at RP $-60 \mathrm{mV}$ and channel activity was evoked by depolarizing the patch for $7 \mathrm{sec}$ to RP +50 $\mathrm{mV}$. Single channel activity was recorded before $(A)$ and after $(B)$ the addition of dibutyryl cAMP. In $B$, the first trace shows channel activity $10 \mathrm{~min}$ after the addition of $2 \mathrm{~mm}$ dibutyryl cAMP to the bath solution. The second through fourth traces are successive traces separated by $1 \mathrm{~min}$ interpulse intervals. $C$ and $D$, Ensemble average currents for channel activity in the absence and presence of dibutyryl cAMP, respectively; eight successive channel responses were summed for each condition. $E$, Time course of latency to inactivation in single channel recordings for the larger conductance channel in the absence and presence of dibutyryl cAMP. The reciprocal of the latency to inactivation was obtained, as described in the Results, for consecutive individual traces. Trials were separated by intervals of $1 \mathrm{~min}$.

channel, like those on the Kv1.5 channel, are mediated, directly or indirectly, by the cAMP-dependent protein kinase, although we have not addressed this question in detail. The finding that somatostatin, a peptide that has previously been shown to activate protein phosphatase $2 \mathrm{~A}$ in $\mathrm{GH}_{4} \mathrm{C}_{1}$ cells (White et al., 1991), can reverse the actions of dibutyryl cAMP provides very strong evidence for this possibility. Previous work has shown that voltage-dependent potassium channels in other systems may be regulated by phosphorylation. For example, conditions that stimulate kinase activity alter the properties of delayed rectifier channels in the squid giant axon (Perozo et al., 1991a,b), and application of the catalytic subunit of the cAMP-dependent protein kinase has been shown to accelerate the rate of $\mathrm{N}$-type inactivation in Drosophila Shaker channels expressed in Xenopus oocytes (Drain et al., 1994).

Activation of the cyclic GMP dependent protein kinase in $\mathrm{GH}_{4} \mathrm{C}_{1}$ cells, in common with exposure of these cells to so- matostatin, activates protein phosphatases (White et al., 1993). Thus, although we found no effect of dibutyryl cGMP on the properties of the small conductance channel under basal conditions, it is possible that agents that stimulate guanylate cyclase may alter the properties of the channel when cAMP levels are elevated.

The existence of two delayed rectifier channels, which respond in different ways to an elevation of cAMP levels, may allow a cell to vary the degree to which its overall potassium current is sensitive to this second messenger. Long-term regulation of the relative levels of expression of the two channels may therefore determine the overall sensitivity of the cells to neurotransmitters and hormones that alter cAMP levels. The properties of $\mathrm{GH}_{4} \mathrm{C}_{1}$ cells closely resemble those of pituitary cells that secrete prolactin and growth hormone (Tashjian, 1979; Gershengorn, 1986). Secretion of these hormones occurs during periods of repetitive firing of action potentials, during which 
intracellular calcium levels are elevated. The amplitude of voltage-dependent potassium currents contributes both to the height and width of action potentials and to the firing pattern of the cells. A decrease in the amplitude of potassium currents and an increase in their inactivation rate could potentiate both action potentials and firing rate, particularly at the end of prolonged periods of stimulation during which the effects of inactivation would be maximal. Thus these changes may comprise part of the mechanism by which agents such as vasoactive intestinal peptide, which elevate cAMP levels in pituitary cells, enhance secretion (Aizawa and Hinkle, 1985).

\section{References}

Aizawa T, Hinkle PM (1985) Differential effects of thyrotropin-releasing hormone, vasoactive intestinal peptide, phorbol ester and depolarization in $\mathrm{GH}_{4} \mathrm{C}_{1}$ rat pituitary cells. Endocrinology 116:909-919.

Bauer CK, Meyerhof W, Schwarz JR (1990) An inward-rectifying K+ current in clonal rat pituitary cells and its modulation by thyrotrophin-releasing hormone. J Physiol (Lond) 429:169-189.

Drain P, Dubin AE, Aldrich RW (1994) Regulation of Shaker $\mathrm{K}^{+}$channel inactivation gating by the CAMP-dependent protein kinasc. Neuron 12:1097-1109.

Dubinsky JM, Oxford GS (1984) Ionic currents in two strains of rat anterior pituitary tumor cells. J Gen Physiol 83:309-339.

Dubinsky JM, Oxford GS (1985) Dual modulation of K channels by thyrotropin-releasing hormone in clonal pituitary cells. Proc Natl Acad Sci USA 82:4282-4286.

Gershengorn MC (1986) Mechanisms of thyrotropin-releasing hormone stimulation of pituitary hormone secretion. Annu Rev Physiol 48:515-526.

Horn R, Marty A (1988) Muscarinic activation of ionic currents measured by a new whole cell recording method. J Gen Physiol 92:145160.

Kramer RH, Kaczmarek LK, Levitan ES (1991) Neuropeptide inhibition of voltage-gated calcium channcls mediated by mobilization of intracellular calcium. Neuron 6:557-563.

Lang DG, Ritchie A (1987) Large and small conductance calciumactivated potassium channels in the $\mathrm{GH}_{3}$ anterior pituitary cell line. Pfluegers Arch 410:614-622.

Levitan ES, Hemmick LM, Birnberg NC, Kaczmarek LK (1991) Dexamethasone increases potassium channel messenger RNA and activity in clonal pituitary cells. Mol Endocrinol 5:1903-1908.

Meyerhof W, Schwarz J, Bauer CK, Hubel A, Richter D (1992) A rat pituitary tumour $\mathrm{K}^{+}$channel expressed in frog oocytes induces a transient $\mathrm{K}^{+}$current indistinguishable from that recorded in native cells. J Neuroendocrinol 4:245-253.

Oxford GS, Wagoner PK (1989) The inactivating $\mathrm{K}^{+}$current in $\mathrm{GH}_{3}$ pituitary cells and its modification by chemical reagents. J Physiol (Lond) 410:587-617.

Perozo E, Vandenberg CA, Jong DS, Bezanilla F (1991a) Single channel studies of the phosphorylation of $\mathrm{K}^{+}$channels in the squid giant axon. I. Steady state conditions. J Gen Physiol 98:1-17

Perozo E, Jong DS, Bezanilla F (1991b) Single channel studies of the phosphorylation of $\mathrm{K}^{+}$channels in the squid giant axon. II. Nonstationary kinetics. J Gen Physiol 98:19-34.

Ritchie AK (1987) Two distinct calcium-activated potassium currents in a rat pituitary cell line. J Physiol (Lond) 385:591-609.

Saal D, Chung S, Kaczmarek LK (1992) Expression and modulation of the Kv1.5 potassium channel in a rat pituitary cell line. Soc Neurosci Abstr 18:76.

Saal D, Chung S, Kaczmarek LK (1993) Expression and Modulation of the Kv1.5 potassium channel in a mouse fibroblast cell line. Soc Neurosci Abstr 19:710.

Simasko SM (1991a) Reevaluation of the electrophysiological actions of thyrotropin-releasing hormone in a rat pituitary cell line. Endocrinology 128:2015-2026.

Simasko SM (1991b) Evidence for a delayed rectifier-like potassium current in the clonal rat pituitary cell line $\mathrm{GH}_{3}$. Am J Physiol 261: E66-E75.

Snyders DJ, Tamkun MM, Bennell PB (1993) A rapidly activating and slowly inactivating potassium channel cloned from human heart. $J$ Gen Physiol 101:513-543.

Swanson R, Marshall J, Smith JS, Williams JB, Boyle MB, Folander $\mathrm{K}$, Luneau CJ, Antanavage J, Oliva C, Buhrow SA, Bennett C, Stein RB, Kaczmarek LK (1990) Cloning and expression of cDNA and genomic clones encoding three delayed rectifier potassium channels in rat brain. Neuron 4:929-939.

Takimoto K, Fomina AF, Gealy R, Trimmer IS, I Levitan ES (1993) Dexamethasone rapidly induces Kv1.5 channel gene transcription and expression in clonal pituitary cells. Neuron 11:359-369.

Tashjian $\Lambda \mathrm{H} \mathrm{Jr}$ (1979) Clonal strains of hormone producing pituitary cells. Methods Enzymol 58:527-535.

White RE, Schonbrunn A, Armstrong DL (1991) Somatostatin stimulates $\mathrm{Cit}^{2+}$-activated $\mathrm{K}^{+}$channels through protein dephosphorylation. Nature 351:570-573.

White RE, Lee AB, Shcherbatko AD, Lincoln TM, Schonbrunn A, Armstrong DL (1993) Potassium channel stimulation by natriuretic peptides through cGMP-dependent dephosphorylation. Nature 361: 263-266. 